\title{
Gene Transfer in the GI Tract and Oral Cavity
}

\author{
Peter Mullany
}

From the Department of Microbiology, Eastman Dental Institute, University of London, 256 Grays Inn Road, London WC1X 8LD, UK

Correspondence to: Peter Mullany, Department of Microbiology, Eastman Dental Institute, University of London, 256 Grays Inn Road, London WC1X 8LD, UK. Tel: + 44 (0)20 7915 1223; Fax: + 44 (0)20 79151127 ; E-mail: p.mullany@eastman.ucl.ac.uk

Microbial Ecology in Health and Disease 2000; Suppl 2: 73-80

Gene transfer is important in spreading antibiotic resistance and other traits such as virulence factors. In this review the molecular mechanisms of gene transfer are outlined and the biological consequences of bacterial gene transfer in the GI tract and the oral cavity (GIOC) are discussed. Finally areas of possible future research aimed at attaining a deeper understanding of the process of gene transfer and the potential for stopping or slowing unwanted transfer are discussed. Key words: gene transfer, conjugation, conjugative transposons, mobile genetic elements.

\section{INTRODUCTION}

Gene transfer is important in spreading antibiotic resistance and other traits such as virulence factors. Both the GI tract and the oral cavity (GIOC) contain a large and diverse community of micro-organisms. Although the bacteria in both sites are considered to be climax communities there are many transient bacteria that pass through, e.g. in food particles, and there is ample opportunity for oral and GI tract bacteria to mix, e.g. the swallowing of oral bacteria, vomiting, and for the flora of one person to mix with others e.g. kissing. This gives huge potential for genetic exchange.

There are three main modes of gene transfer in bacteria: transduction, transformation and conjugation. All the available evidence so far indicates that transformation and transduction are responsible for transferring genetic information between closely related bacteria; however, some of these transfer events do have important biological consequences (some of which will be reviewed below). On the other hand genes can be transferred by conjugation over large phylogenetic distances, for example, between Grampositive and Gram-negative bacteria (1) and even between prokaryotes and eukaryotes (2).

\section{MECHANISM OF CONJUGATION}

Conjugation is defined as the direct transfer of DNA from the cytoplasm of a donor to the cytoplasm of a recipient. Conjugation is mediated by a variety of conjugative plasmids and conjugative transposons; these conjugal elements have also been shown to be capable of mobilising non-conjugative but mobilisable plasmids and transposons; finally other mobile elements (non conjugative transposons, integrative plasmids, mobile introns and IS sequences) can integrate into the conjugative element and be transferred with the conjugal or mobilisable element. Some of these mobile genetic elements have also been used as tools for the genetic analysis of a variety of bacteria, including many organisms that are important pathogens. For example in Clostridium difficile the only means of genetic manipulation is to use the conjugative transposon Tn916 as a shuttle conjugative transposon (3).

The molecular mechanisms of conjugative transfer between Gram-negative bacteria have been well characterised (for a review see 4). The F-plasmid is the paradigm for the study of bacterial conjugation. This plasmid has approximately 40 genes in its transfer region, taking up $33.3 \mathrm{~kb}$. A plasmid-encoded pilus is produced (sometimes called sex pili) which is required for conjugation. At least 15 genes are required for pilus production and assembly. The sex pili are required for establishing the first intercellular contact between the donor and recipient. After contact has been established the pili are thought to disassemble leading to the formation of a DNA transport pore across the cell envelopes. Most conjugative plasmids from Gram-negative organisms produce sex pili.

Transfer of the plasmid is initiated by strand- and sequence-specific cleavage at a site called nic in the origin of transfer oriT. A single strand is transferred to the recipient; second strand synthesis then occurs in donor and recipient. The nicking process at oriT requires the plasmidencoded protein TraI (nicking and helicase activity); this protein also remains attached to the DNA and is trans- 


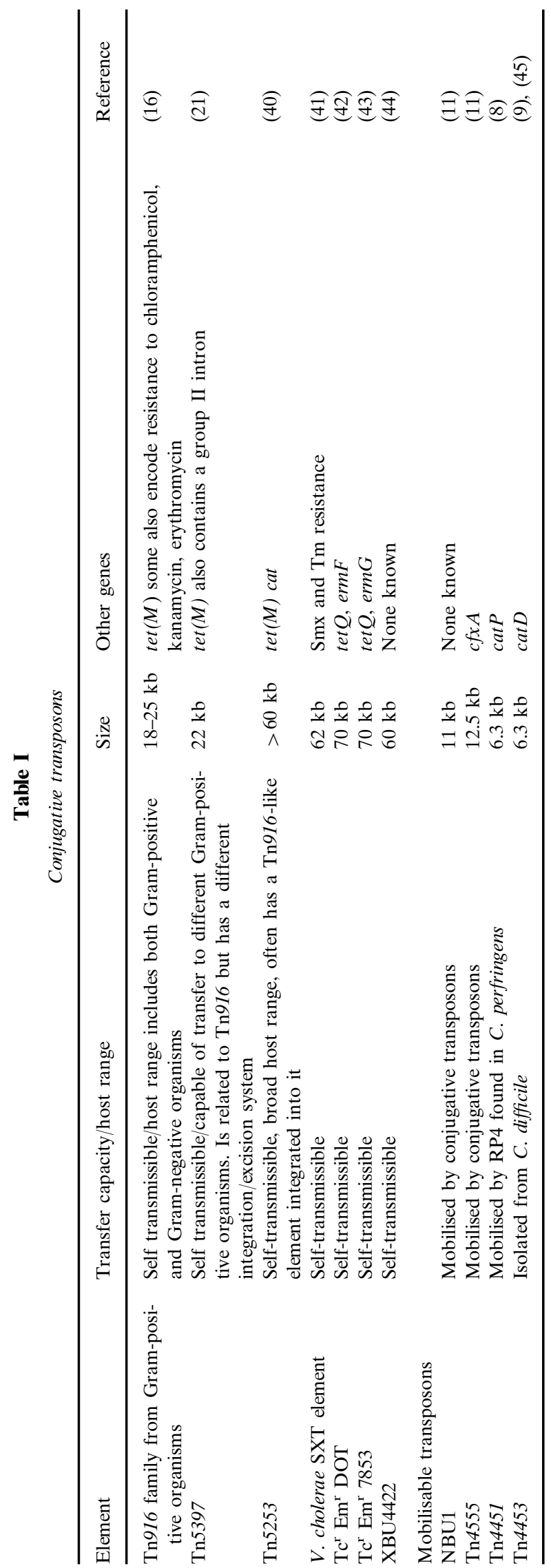

ferred to the recipient. Other plasmid encoded proteins TraM and TraY and the host factor IHF are required for this process.

Conjugative transfer between Gram-positive cells is not as well understood, although functional oriT sequences have been identified in the conjugative plasmid pIP501 (5) the conjugative transposon Tn916 (6) the staphylococcal plasmid, pGO1 (7) the mobilisable transposon from Clostridium perfringens $\mathrm{Tn} 4451$ (8) and the mobilisable transposon Tn4453 from Clostridium difficile (9).

The mechanism of conjugation in Gram-positive organisms may differ significantly from that observed in Gramnegative organisms as the transfer region is appreciably smaller, for example, in Tn916 the transfer region only consists of 11 genes, compared to 40 for F-like plasmids (10). Also pili do not appear to have a role in conjugation in Gram-positive organisms.

\section{GENETIC ELEMENTS PROMOTING CONJUGATION}

Plasmids

Plasmids are common in both Gram-positive and Gramnegative organisms isolated from the GIOC (11). Some plasmids, such as members of the IncP group, have been shown to have a very large host range, being able to mobilise themselves and small non-autotransferring plasmids into both Gram-positive and Gram-negative hosts (12). However, members of this group do not normally replicate in Gram-positive organisms (12). Large conjugal plasmids have also been found in Gram-positive organisms (e.g. pAM $\beta 1$, pGO1 and pIP501). These plasmids have a broad host range in Gram-positive organisms and can mobilise other plasmids (see below) (12).

\section{Conjugative transposons}

Until recently plasmids were thought to be the only elements transferred by conjugation. However, there is at least one other type of conjugal element, the conjugative transposon $(13,14)$. Table I lists some of the conjugative transposons and the elements they mobilise. There is no hard and fast definition of what constitutes a conjugative transposon and many different types of elements from different bacteria have been termed conjugative transposons. However, the elements listed in Table I do have some features in common. Conjugative transposons are normally integrated into the host genome. To transfer they excise and form a circular intermediate, one strand of which transfers to the recipient organism, the remaining single strand is used as a template for second strand synthesis in both the donor and recipient. The element can now insert into the genome in both donor and recipient using an element encoded site-specific recombinase; this recombinase varies in different conjugative transposons $(15,14)$. Because most of the conjugative transposons examined to date have a very broad host range, the 
site-specific recombinases must be functional in different genetic backgrounds. In fact conjugative transposons are probably the most promiscuous genetic elements known; for example, members of the Tn916 family have been found in, or transferred into at least 52 different genera $(14,16)$. These elements have been responsible for the rapid growth of antibiotic resistance in many different bacteria $[(14,16)$ and Table I].

The conjugative transposons are sociable elements. The presence of one conjugative transposon in the genome is no bar to related transposons entering the same genome. This is unlike plasmids, which exhibit the phenomenon of incompatibility and surface exclusion, and some non-conjugative transposons which can confer immunity to further transposition events. Therefore, conjugative transposons have the opportunity to interact with each other and some interesting composite elements can result from these interactions (see below). Another potential advantage that conjugative transposons have over plasmids is that when a plasmid arrives in a new cell it has to be able to stably replicate, whereas conjugative transposons integrate into the genome. This property extends the host range of conjugative transposons.

\section{MOBILISABLE GENETIC ELEMENTS}

Mobilisable genetic elements are not self-transmissible but can transfer between species via conjugation in the presence of a helper element. The basic requirement in order to be mobilised is the presence of an oriT and frequently a $m o b$ gene, which encodes a protein which specifically nicks the oriT site and is required to help form the relaxosome prior to transfer. Other transfer functions are provided by the mobilising element.

\section{Mobilisable plasmids}

Mobilisable plasmids have been found in both Gram-positive and Gram-negative organisms. They have been shown to be mobilised both by conjugative plasmids and conjugative transposons (14). Mobilisable plasmids can be mobilised in both cis and trans. When mobilised in trans they make use of the helper molecule's transfer functions without becoming physically linked to this molecule. However, when mobilised in cis they form a co-integrate (a process often mediated by non-conjugative transposons or IS sequences) with the conjugal molecule; this can then resolve in the recipient. In order to survive the new host the mobilisable plasmid must be able to replicate. Some mobilisable plasmids (e.g. members of the rolling circle family) can replicate in many different host genera (17).

\section{Mobilisable transposons}

So far mobilisable transposons have only been found in Bacteroides species and in Clostridium perfringens and Clostridium difficile (11, 8, 9). Five Bacteroides mo- biliseable transposons have been found; these range in size from 9 to $12 \mathrm{~kb}$ (11). The Clostridial mobilisable transposons are around $6 \mathrm{~kb}$ and are all closely related to each other $(8,9)$.

Mobilisable transposons have to excise from the genome and form a circular intermediate that does not appear to be capable of independent replication. The circular form is the transpositional and conjugal intermediate. Although transfer is dependant on the conjugal molecule, integration and excision is not $(11,8,9)$. The mobilisable elements can integrate into the chromosome of the recipient in the absence of the conjugal molecule. The mechanism of insertion and excision differs in the different mobilisable transposons. Also some of the mobilisable transposons carry other genes not concerned with transfer (e.g. antibiotic resistance genes).

\section{PATHOGENICITY ISLANDS}

Virulence determinants are often located on the chromosome of particular pathogens where they are situated together in blocks, so called virulence cassettes or virulence blocks. Particular regions of chromosomaly encoded virulence genes have also been termed pathogenicity islands (Pais) (18). Pais are defined according to the following criteria.

1. Carriage of virulence genes

2. Presence in pathogenic strains and absence or sporadic distribution in less-pathogenic strains of one species or a related species

3. Different $\mathrm{G}+\mathrm{C}$ content in comparison to DNA of host bacteria

4. Occupation of large chromosomal regions (often $>30$ $\mathrm{kb})$

5. Represents compact, distinct genetic units, often flanked by direct repeats

6. Associated with tRNA genes and/or insertion sequence (IS) elements at their boundaries. As the sequence of tRNA genes are conserved in different hosts, the ability to enter these genes potentially gives Pais a broad host range

7. Presence of (often cryptic) mobility genes (IS elements integrases, transposases, origins of plasmid replication)

8. Instability

Elements fitting this criteria have been found extensively in both Gram-positive and Gram-negative pathogens (18, 19). Pais therefore contribute to the genetic flexibility of certain bacterial species and are likely to be involved in bacterial evolution. It is also speculated that genetic elements similar to Pais exist which have roles in secretion (secretion islands), resistance to antibiotics (resistance islands) or in the physiology of micro-organisms (metabolic islands). 


\begin{tabular}{|c|c|c|c|}
\hline Name & Elements involved & Properties & Reference \\
\hline $\operatorname{Tn} 3872$ & Tn916-like and Tn917-like & $\begin{array}{l}\text { So far has been found in Streptococcus pneumoniae where it confers } \\
\text { tetracycline and erythromycin resistance }\end{array}$ & $(27)$ \\
\hline $\operatorname{Tn} 5385$ & $\operatorname{Tn} 916, \operatorname{Tn} 4001, \operatorname{Tn} 552$, IS1216 & $\begin{array}{l}\text { Large composite element that confers resistance to tetracycline, } \\
\text { erythromycin, mercury, gentamicin, } \beta \text {-lactamase and streptomycin }\end{array}$ & $(28)$ \\
\hline \multirow[t]{2}{*}{$\operatorname{Tn} 5253$} & $\begin{array}{l}\text { Tn916-like and a large con- } \\
\text { jugative transposon }\end{array}$ & Confers tetracycline resistance, originally found in the pneumococcus & $(46)$ \\
\hline & R751, Tc ${ }^{\mathrm{r}} \mathrm{ERL}, \mathrm{Tn} 4351$ & $\begin{array}{l}\text { Association of a conjugative plasmid, conjugative transposon and non- } \\
\text { conjugative transposon. This association increases the host range of both } \\
\text { plasmid and conjugative transposon }\end{array}$ & (44) \\
\hline pTB19 & $\begin{array}{l}\text { Theta type plasmid and } \\
\text { pTB } 913\end{array}$ & $\begin{array}{l}\text { Association between a rolling circle and a theta type of conjugative } \\
\text { plasmid }\end{array}$ & $(47)$ \\
\hline
\end{tabular}

\section{OTHER MOBILE ELEMENTS}

Other than the self transferable and mobilisable plasmids and transposons there are genetic elements which can 'hitch-hike' on these elements by integrating into the transferable elements.

\section{Integrons}

Integrons are genetic elements that contain the determinants of a site-specific recombination system that recognises and captures mobile gene cassettes. These cassettes are often antibiotic resistance genes. In this way integrons can build up an array of antibiotic resistance genes (20). Integrons can be maintained in both plasmids and transposons. So far integrons have only been found in Gramnegative organisms.

\section{Non conjugative transposons}

The properties of non-conjugative transposons have been reviewed extensively elsewhere. They have been found in all bacteria for which they have been sought and have been found to contain genes encoding antibiotic resistance, virulence factors and the ability to metabolise certain exotic substrates.

\section{Mobile introns}

Group I and group II introns were originally found in organelle genomes. Over the last few years these elements have been increasingly found in bacteria. In bacteria the introns are almost invariably associated with other mobile genetic elements, including conjugative transposons (21) conjugative plasmids (22) non-conjugative transposons (23) and other mobile elements $(24,25)$. Recently it has been proven that the bacterial introns are capable of homing (transposition to an intronless allele) (26).

\section{Composite genetic elements}

As noted above, non-conjugative elements form associations with conjugative elements (e.g. the insertion of a transposon into a plasmids). However, conjugative ele- ments also form physical associations with each other. Some of the types of genetic associations are shown in Table II. As can be seen from the table, different types of conjugative transposons have been shown to associate with each other, with plasmids and other mobile elements. This association between different mobile elements can broaden each others' host range, giving the new composite element access to a vast amount of genetic information and the potential to generate more novel elements (27-29). This type of co-operation between mobile elements is a powerful means of generating rapid evolutionary change.

\section{HORIZONTAL GENE TRANSFER IN THE GIOC}

From the above discussion it can be appreciated that there are many different gene transfer elements in bacteria. These elements play a critical role in the emergence of new pathogenic organisms by the dissemination of virulence factors and antibiotic resistance genes. In this section of the review we will examine the evidence that horizontal transfer has taken place in the GIOC and then examine host factors that modulate gene transfer.

\section{Evidence for horizontal gene transfer in the GIOC}

Examples of proven gene transfer in the GIOC include the finding that enterotoxin plasmids can be transferred between two E. coli strains in the intestines of newly weaned guinea pigs (30); that the conjugative transposon $\operatorname{Tn} 916$ can be transferred between different genera of Gram-positive bacteria in the GI tract of germ-free mice (31); lysogenic conversion of Corynebacterium diptheriae in humans (32); and the demonstration that the conjugative transposon Tn5397 can be transferred in a model oral biofilm to different Gram-positive oral bacteria (33). Other examples of gene transfer in vivo have been reviewed by Mel and Mekalanos (34).

Another line of evidence supporting horizontal gene transfer in the GIOC comes from the finding that the same antibiotic resistance genes are found in different hosts. Due to the degenerate nature of the genetic code, if copies 
of the same gene in different bacterial species are $95-100 \%$ identical at the DNA sequence level, they are virtually guaranteed to have been acquired by horizontal gene transfer. Some examples of transfer of antibiotic resistance genes between bacteria from diverse habitats are shown in Table III. As can be seen resistance genes from bacteria used in the production of foodstuff can find their way into intestinal bacteria as can resistance genes from animal origin and from oral bacteria. This shows that gene transfer can and does take place both between GIOC bacteria and between these bacteria and organisms from other sources. Often the genes were associated with transmissible agents and could be transferred in the laboratory. In other cases the genes could not be transferred in the laboratory either because the mobile element that was originally responsible for transfer had been lost or because the conditions required for transfer could not be repeated in the laboratory (see below for more details of the conditions required for gene transfer).

The above experiments show beyond doubt that gene transfer takes place in the GIOC. This introduces the very real possibility that normal commensal organisms can act as reserves of antibiotic resistance genes and virulence factors.

\section{SIGNALS THAT INDUCE GENE TRANSFER}

Expression of the genes required for horizontal transfer are tightly regulated. Mobile elements have evolved control mechanisms that minimise the metabolic and other burdens (e.g. phage sensitivity) on the host. These control mechanisms also ensure that gene transfer occurs at the most beneficial time for the element. This section of the review discusses what is known about some of these control mechanisms. This information is important so that an appreciation can be gained of the link between environmental conditions and gene transfer frequency.

\section{Table III}

Examples of virtually identical antibiotic resistance genes in found in distantly related species

\begin{tabular}{lll}
\hline Gene & Species & Site of isolation \\
\hline tetQ & Bacteroides spp & Human colon \\
& $\begin{array}{l}\text { Porphyromonas spp } \\
\text { Prevotella ruminicola }\end{array}$ & Human mouth \\
erm $G$ & Bacteroides spp & human colon \\
& Bacillus sphaericus & soil \\
tet $K$ & Staphylococcus xylos & cheese \\
& Staphylococcus aureus & human infection \\
tet $S$ & Lactococcus lactis & cheese \\
& Listeria monocytogenes & human infection \\
cat & Enterococcus faecalis & sausage \\
& Staphylococcus aureus & human Infection \\
\hline
\end{tabular}

Adapted from (38) and (48).

\section{F-like plasmid transfer}

F-like plasmids are frequently responsible for the spread of antibiotic resistance genes in the enterobacteriaciae. The F-like systems are normally switched off by FinOP, an antisense RNA transcript. Initiation of transfer gene expression may be triggered by direct signals though activator proteins. These proteins respond to certain physiological conditions such as oxygen availability, cAMP levels, temperature and growth phase. Also apparently occasional random perturbations of the expression of the regulatory proteins can induce transfer. In the new recipients there will be a burst of activity of the transfer genes before the negative regulators have time to repress the process. This will allow a plasmid to spread though a population of suitable recipients until all bacteria contain the element. The exact physiological conditions that favour transfer have not yet been worked out.

\section{IncP plasmids}

These plasmids have complex regulatory circuits that are thought to ensure that the plasmid transfer genes are expressed at low level that does not add a significant burden to the host cell. There is little data available about the environmental signals that promote transfer.

\section{The pheromone responding plasmids of Enterococci}

These plasmids respond to pheromones that are secreted by plasmid free recipients (35). The pheromones trigger the donor cell to express transfer functions. Thus pheromone accumulation indicates to donors that recipients are in close proximity. The plasmids prevent their host mating with other plasmid-positive bacteria by blocking pheromone activity by inhibition of its synthesis. Some of the pheromone responding plasmids encode virulence factors and there are also suggestions that transfer of these plasmids is enhanced when the Enterococci are in their mammalian host.

\section{Staphylococcal and Streptococcal plasmids}

Although some details of the control mechanisms of these plasmids have been established, there is little information regarding the environmental signals to which they respond. Study of the control mechanisms do indicate that these plasmids have complex regulatory systems (12).

\section{Conjugative transposons}

The conjugative transposons $\operatorname{Tn} 916$ and $\operatorname{Tn} 5397$ are very closely related but have a completely different integration and excision system (15). However, the control mechanisms are likely be similar in the two (36). Both elements respond to the presence of tetracycline by an increase in expression of the excision and transfer genes. This results from a tetracycline induced increase in expression of the tet $(M)$ gene, presumably by an attenuation mechanism, 
which reads though into 2 positive regulatory genes and negative regulatory gene (the latter gene is transcribed in the opposite direction to the majority of genes in $\mathrm{Tn} 916$ ). This results in increased excision frequency of the transposon. The Bacteroides conjugative transposons have been shown to increase their frequency of transfer, in the presence of tetracycline, by more than 100-fold (14). The regulatory system behind this phenomenon has not been completely elucidated but it requires the participation of a two-component regulatory system encoded by the rte (sensor kinase) and $r t b$ (regulator genes). These genes are part of an operon in which the tetracycline resistance gene tet $Q$ is the first gene. The Bacteroides conjugative transposons also mobilise other mobile elements in the presence of tetracycline. Thus, in the case of the conjugative transposons, antibiotics not only select for resistant strains but stimulate transfer of resistance genes. Therefore, the use of low levels of antibiotics may have a greater effect on the resident microflora than originally thought.

\section{Gene transfer in Vibrio cholera in the mammalian intestine}

This system will be discussed as it provides an example of a well characterised system in which the environment of the host modulates gene transfer.

The CTX element of $V$. cholerae is a filamentious phage which contains the genes for several virulence factors of $V$. cholerae, including the cholera toxin (CT) (34). The attachment site for the phage is the toxin co-regulated pilus (TCP). TCP is only produced efficiently in the mammalian intestine and is required for attachment of $V$. cholerae to the intestinal epithelium. In the mammalian gut therefore non-toxigenic strains can undergo a lysogenic conversion to $\mathrm{CT}+$ when there is a mixed infection with a strain containing the CTX phage. The lysogenic conversion occurs up $10^{6}$ times more efficiently in the intestine than in vivo. Thus the CTX phage is a highly evolved transmissible agent which can spread virulence factors in the GI tract.

The TCP is a member of a large family of pili (type IV) that are involved in virulence, typically by promoting adhesion. These pili are also often involved in DNA uptake or DNA transfer events. Furthermore, type IV pili are preferentially expressed in vivo. Therefore, it follows that a variety of horizontal gene transfer events dependant on this class of proteins are probably enhanced in the host and modulated by host environmental signals.

\section{USE OF CONJUGAL ELEMENTS IN GENETIC ANALYSIS OF BACTERIA}

Mobile elements have been used extensively in genetic analysis of bacteria and other organisms. Conjugal elements have been used to transfer genes and vectors of interest into a wide-range of different bacteria. Of particular use in this regard has been the broad host range conjugal plasmid RP4 and the conjugative transposon Tn916. The use of mobile elements has allowed a revolution in the genetic analysis of very many different organisms.

\section{QUESTIONS FOR FUTURE RESEARCH}

Approaches for future work on gene transfer can be divided into three general areas: 1) Mechanistic; 2) Discovery; 3) Ecological. It is expected that there will be some overlap between these areas and it is important workers with expertise in these different areas work closely together.

\section{Mechanistic}

Further characterisation of the mobility mechanisms, the specific questions are outlined below.

Much more knowledge is needed on the conjugation process itself, particularly in Gram-positive organisms and in the conjugative transposons. For example, what are the environmental signals that modulate gene transfer and how are these signals sensed by mobile elements?

What are the host factors that conjugal molecules require? This is important as knowledge of host factors will allow us to anticipate which organisms particular genetic elements can move into. Related to this we need to know the host range of different mobile elements.

\section{Discovery}

Have we found all the mobile elements that are out there? Would it be worth carrying out a systematic program of discovery to look for new gene transfer elements and new gene transfer mechanisms?

What type of genes are carried on mobile elements? DNA sequencing projects might answer some of these questions?

Do metabolic, resistance and secretion islands exist and if so what is their host range?

\section{Ecological}

What are the factors that drive gene transfer in nature?

What are the selective pressures that lead to transfer of mobile elements, both containing antibiotic resistance genes and containing genes for virulence factors and other specialised metabolic functions? Can we predict what conditions will lead to gene transfer and if so can we then manipulate the environment to stop unwanted transfer and encourage desirable transfer events?

How typical are antibiotic resistance genes as markers of horizontal gene transfer? These genes are found in mobile elements and may also have evolved promoters that express in many different hosts, is this also true of genes on mobile elements that encode virulence factors? This question may be answered through the analysis of genome sequence data bases, as more bacterial genomes are se- 
quenced we can see how many and what type of genes are subject to horizontal gene transfer.

More in vivo work in animal models should be done using bacteria that have been marked with different genetic elements and then following them through model systems. The animals can be treated with different antibiotics and other conditions to see what effect these have on the transfer of different genetic elements.

At a recent meeting of the group Reservoirs of Antibiotic Resistance (ROAR http:www.roar.antibiotic.org) the following questions were identified: 1) To what extent do commensal bacteria exchange resistance genes with each other and how likely are such transfers to have an effect on human health; 2) What human practises make the greatest contribution to increasing resistance levels in the commensal bacteria, stimulating the transfer of resistance genes; 3 ) What are the best ways to monitor the movement of genes in strains of resistant commensal bacteria; 4) How should the data be interpreted? Is it possible to develop methods for predicting the emergence of a resistance problem in a bacterial population?

How does one monitor gene transfer in natural situations? Is there any new technology available to monitor this? Some of the technology being used by environmental microbiologists may be useful here (e.g. see 37).

We need to know if antibiotic resistance genes are present in probiotics etc. and if they can transfer to human commensals and then on to human pathogens. There is some evidence that this can happen. There is evidence that bacteria in cheese can transfer antibiotic resistance genes to intestinal organisms (38).

What is the role of mobile elements, including pathogenicity islands, in mediating the spread of virulence factors and the generation of new pathogens?

What effect does the potential for gene transfer have on the release of genetically modified organisms?

\section{CONCLUDING REMARKS}

This review has shown that in nature there are a vast number of mobile elements that are capable of mediating gene transfer. We have also seen that many of these elements get together to form new and more promiscuous elements given the right selective pressures. There is now overwhelming evidence that bacteria from food products, soil and other environmental sources can exchange genetic information with the flora in the GIOC.

As well as antibiotic resistance determinants, virulence factors have been shown to be spread by horizontal gene transfer and in some cases these transfer events are promoted by host factors. Furthermore, some virulent organisms use conjugation-like system to export molecules that interact with the host (39). Host factors may also modulate the transfer of antibiotic resistance determinants. Thus horizontal gene transfer contributes both to the generation of new pathogens and to the generation of both old and new pathogens that are antibiotic resistant.

The next challenge is to understand what implications this exchange has for human health and what we can do about it. This requires systematically measuring the rate of genetic exchange in the GIOC, seeing how this exchange is mediated, and implementing strategies to minimise gene exchange (if required). This requires expertise in bacterial genetics, ecology, biochemistry and the access to patients and animal models.

\section{ACKNOWLEDGEMENTS}

This review has been carried out with financial support from the Commission of the European Communities, Agriculture and Fisheries (FAIR) specific RTD programme PL98 4230 'Intestinal Flora: Colonisation Resistance and Other Effects'. It does not necessarily reflect its views and in no way anticipates the commission's future policy in this area.

\section{REFERENCES}

1. Trieu-Cuot P, Carlier C, Martin P, Courvalin P. Plasmid transfer by conjugation from Escherichia coli to Gram-positive bacteria. FEMS Microbiol Lett 1987; 8: 289-94.

2. Heinemann JA, Sprague GF Jr. Bacterial conjugative plasmids mobilise DNA transfer between bacteria and yeast. Nature 1989; 340: 205-9.

3. Mullany P, Wilks M, Puckey L, Tabaqchali S. Gene cloning in Clostridium difficile using $\mathrm{Tn} 916$ as a shuttle conjugative transposon. Plasmid 1994; 31: 320-3.

4. Lanka E, Wilkins BM. DNA processing reactions in bacterial conjugation. Annu Rev Biochem 1995; 64: 141-69.

5. Wang A, Macrina FL. Streptococcal plasmid pIP501 has a functional oriT site. J Bacteriol 1995; 177: 4199-206.

6. Jaworski DD, Clewell DB. A functional origin of transfer (oriT) on the conjugative transposon Tn916. J Bacteriol 1995; 177: 6644-51.

7. Climo MW, Sharma VK, Archer GL. Identification and characterisation of the origin of transfer (oriT) and a gene(nes) encoding a single stranded endonuclease on the staphylococcal plasmid pGO1. J Bacteriol 1996; 178: 4975-83.

8. Crellin PK, Rood JI. Tn4451 from Clostridium perfringens is a mobilisable transposon that encodes the functional Mob protein, TnpZ. Mol Microbiol 1998; 27: 631-42.

9. Lyras D, Storie C, Huggins AS, Crellin PK, Bannam TL, Rood JI. Chloramphenicol resistance in Clostridium difficile is encoded on Tn4453 transposons that are closely related to Tn4451 from Clostridium perfringens. Antimicrob Agents Chemother 1998; 23: 784-6.

10. Flannagan SE, Zitzow LA, Su YA, Clewell DB. Nucleotide sequence of the $18 \mathrm{~kb}$ conjugative transposon $\mathrm{Tn} 916$ from Enterococcus faecalis. Plasmid 1994; 32: 350-4.

11. Smith CJ, Tribbble GD, Bayley DP. Genetic elements of Bacteroides species: a moving story. Plasmid 1998; 40: 12-29.

12. Zatyka M, Thomas CM. Control of genes for conjugative transfer of plasmids and other mobile elements. FEMS Microbiol Rev 1998; 21: 291-319.

13. Clewell DB, Flannagan SE. The conjugative transposons of Gram-positive bacteria. In: Clewell DB, ed. Bacterial conjugation. New York: Plenum Press, 1993: 369-93.

14. Salyers AA, Shoemaker NB, Stevens AM, Lhing-Yew L. Conjugative transposons: an unusual and diverse set of inte- 
grated gene transfer elements. Microbiol Rev 1995; 59: 57990.

15. Wang H, Roberts AP, Lyras D, Rood JI, Wilks M, Mullany P. Characterisation of the ends and target sites of the novel conjugative transposon Tn5397 from Clostridium difficile: excision and circularisation is mediated by the large resolvase TndX. J Bacteriol 2000; 182: 3775-83.

16. Rice LB. Tn916 family of conjugative transposons and dissemination of antimicrobial resistance determinants. Antimicrob Agents Chemother 1998; 42: 1871-7.

17. Charpentier E, Gerbaud G, Courvalin P. Conjugative mobilisation of the rolling circle plasmid pIP823 from Listeria monocytogenes BM4293 among Gram-positive and Gramnegative bacteria. J Bacteriol 1999; 181: 3368-74.

18. Hacker J, Blum-Oehler G, Mühldorfer I, Tschäpe H. Pathogenicity islands of virulent bacteria: structure, function and impact on microbial evolution. Mol Microbiol 1997; 23: 1087-9.

19. Lindsay JA, Ruzin A, Ross HF, Kurepina N, Novick RP. The gene for toxic shock toxin is carried by a family of mobile pathogenicity islands in Staphylococcus aureus. Mol Microbiol 1998; 29: 527-43.

20. Recchia GD, Hall RM. Origins of the mobile gene cassettes found in integrons. Trends Microbiol 1997; 5: 389-94.

21. Mullany P, Pallen M, Wilks M, Tabaqchali S. A Group II intron in a conjugative transposon from the Gram-positive bacterium, Clostridium difficile. Gene 1996; 174: 145-50.

22. Yeo CC, Tham JM, Yap MWC, Poh CL. Group II intron from Pseudomonas alcaligenes NCIB 9867 (P25X): Entrapment in plasmid RP4 and sequence analysis. Microbiology 1997; 143: 2833-40.

23. Huang C-C, Narita M, Yamagata T, Itoh Y, Endo G. Structure analysis of a class II transposon encoding the mercury resistance of the Gram-positive bacterium Bacillus megaterium MB1, a strain isolated from Minamata Bay, Japan. Gene 1999; 234: 361-9.

24. Mills DA, McKay LL, Dunny GM. Splicing of a group II intron involved in the conjugative transfer of pRS01 in Lactococci. J Bacteriol 1996; 178: 3531-8.

25. Shearman C, Godon JJ, Gasson M. Splicing of a group II intron in a functional transfer gene of Lactococcus lactis. Mol Microbiol 1996; 21: 45-53.

26. Cousineau B, Smith D, Lawrence-Cavanagh S, Mueller JE, Yang J, Mills D, Manias D, Dunny G, Lambowitz AM, Belfort M. Retrohoming of a bacterial group II intron: mobility via complete reverse splicing, independent of homologous recombination. Cell 1998; 94: 451-62.

27. McDougal LK, Tenover FC, Lee LN, Kamile J, Patterson JE, Jorgensen JH, LeBlanc DJ. Detection of Tn917-like sequences within a Tn916-like conjugative transposon (Tn3872) in erythromycin-resistant isolates of Streptococcus pneumoniae. Antimicrob Agents Chemother 1998; 42: 2312-8.

28. Rice LB, Carias LL. Transfer of Tn5385, a composite multiresistance chromosomal element from Enterococcus faecalis. J Bacteriol 1998; 180: 714-21.

29. Shoemaker NB, Salyers AA. Facilitated transfer of IncP $\beta$ R751 derivatives from the chromosome of Bacteroides uniformis to Escherichia coli recipients by a conjugative Bacteroides tetracycline resistance element. J Bacteriol 1987; 169: 3160-7.

30. Gyles C, Falkow S, Rollins L. In vivo transfer of an Escherichia coli enterotoxin plasmid possessing genes for drug resistance. Am J Vet Res 1978; 39: 1438-41.
31. Doucet-Populaire F, Trieu-Cuot P, Dosbaa I, Andremont A, Courvalin P. Conjugal transfer of plasmid DNA from Enterococcus faecalis to Escherichia coli in digestive tracts of gnotobiotic mice. Antimicrob Agents Chemother 1992; 35: $185-7$.

32. Pappenheimer AM Jr, Murphy JR. Studies on the molecular epidemiology of diphtheria. Lancet 1983; 2: 923-6.

33. Roberts AP, Pratten J, Wilson M, Mullany P. Transfer of a conjugative transposon, Tn5397 in a model oral biofilm. FEMS Microbiol Lett 1999; 177: 63-6.

34. Mel SF, Mekalanos JJ. Modulation of horizontal gene transfer in pathogenic bacteria by in vivo signals. Cell 1996; 87: 795-8.

35. Dunny G, Yuhasz M, Ehrenfeld E. Genetic and physiological analysis of conjugation in Streptococcus faecalis. J Bacteriol 1982; 151: 855-9.

36. Celli J, Trieu-Cuot P. Circularisation of Tn916 is required for expression of the transposon-encoded transfer functions: characterisation of long tetracycline-inducable transcripts reading through the attachment site. Mol Microbiol 1998; 28: 103-17.

37. Droge M, Puhler A, Selbitschka W. Horizontal gene transfer in terrestrial and aquatic habitats as assessed by microcosm and field studies. Biol Fert Soils 1999; 29: 221-54.

38. Teuber M, Perreten V, Wirsching F. Antibiotikumresistente bakterien: eine neue dimension in der lebensmittel-mikrobiologie. Lebensmittel-Technologie 1996; 29: 182-99.

39. Segal G, Shuman HA. Intracellular multiplication and human macrophage killing by Legionella pneumophila are inhibited by conjugal components of IncQ plasmids RSF1010. Mol Microbiol 1998; 30: 197-208.

40. Shoemaker NB, Salyers AA. Dnase resistant transfer of chromosomal cat and tet insertions by filter mating in pneumococcus. Plasmid 1980; 3: 80-7.

41. Waldor MK, Tschape H, Mekalanos JJ. A new type of conjugative transposons encodes resistance to sulfamethoxazole, trimethoprim and streptomycin in Vibrio cholerae O139. J Bacteriol 1996; 178: 4157-65.

42. Stevens AM, Shoemaker NB, Salyers AA. Tetracycline regulation of genes on Bacteroides conjugative transposons. J Bacteriol 1993; 175: 6134-41.

43. Cooper AJ, Shoemaker NB, Salyers AA. The erythromycin resistance gene from the Bacteroides conjugative transposon $\mathrm{Tc}^{r} \mathrm{Em}^{\mathrm{r}} 7853$ is nearly identical to erm $G$ from Bacillus sphaericus. Antimicrob Agents Chemother 1996; 40: 506-8.

44. Shoemaker NB, Salyers AA. A cryptic 65-kilobase pair transposon-like element isolated from Bacteroides uniformus has homology with Bacteroides conjugal tetracycline resistance elements. J Bacteriol 1990; 172: 1694-702.

45. Wren B, Mullany P, Clayton C, Tabaqchali S. Molecular cloning and genetic analysis of chloramphenicol acetyltransferase determinant from Clostridium difficile. Antimicrob Agents Chemother 1988; 32: 1213-7.

46. Ayoubi P, Kilic OA, Vijayakumar MN. Tn5253, the pneumococcal (cat tet) BM6001 element is a composite structure of two conjugative transposons, Tn5251 and Tn5252. J Bacteriol 1991; 173: 1617-22.

47. Oskam L, Hillenga DJ, Venema G, Bron S. The integrated state of the rolling-circle plasmid pTB913 in the composite Bacillus plasmid pTB19. Mol Gen Genet 1992; 233: 462-8.

48. Salyers AA, Shoemaker NB. Resistance gene transfer in anaerobes: new insights, new problems. Clin Infect Dis 1996; 23 (Suppl): S36-43. 